\title{
The Influence of Purification of Carp Collagen Used in a Novel Composite Graft with Sandwich Construction of the Wall on Its Biological Properties and Graft Patency Rates
}

\author{
P. MITAS $^{1^{*}}$, T. GRUS ${ }^{1^{*}}$, L. LAMBERT ${ }^{2}$, M. MLCEK ${ }^{3}$, H. CHLUP $^{4}$, E. HONSOVA $^{5}$, \\ M. DOHNALOVA ${ }^{1}$, T. SUCHY ${ }^{\mathbf{6}}$, A. BURGETOVA ${ }^{2}$, J. LINDNER $^{1}$, M. SPACEK ${ }^{1}$ \\ *These authors contributed equally to this paper
}

${ }^{1}$ Second Department of Surgery - Department of Cardiovascular Surgery, First Faculty of Medicine, Charles University and General University Hospital, Prague, Czech Republic, ${ }^{2}$ Department of Radiology, First Faculty of Medicine, Charles University and General University Hospital in Prague, Prague, Czech Republic, ${ }^{3}$ Institute of Physiology, First Faculty of Medicine, Charles University, Prague, Czech Republic, ${ }^{4}$ Department of Mechanics, Biomechanics and Mechatronics, Faculty of Mechanical Engineering, Czech Technical University in Prague, Prague, Czech Republic, ${ }^{5}$ Department Pathology, Institute for Clinical and Experimental Medicine, Prague, Czech Republic, ${ }^{6}$ Institute of Rock Structure and Mechanics of the Czech Academy of Sciences, Prague, Czech Republic.

Received January 12, 2019

Accepted May 2, 2019

Epub Ahead of Print June 6, 2019

\begin{abstract}
Summary
We compared graft outcome between two types of a novel composite three-layer carp-collagen-coated vascular graft in low-flow conditions in a sheep model. Collagen in group $A$ underwent more cycles of purification than in group $B$ in order to increase the ratio between collagen and residual fat. The grafts were implanted end-to-side in both carotid arteries in sheep (14 grafts in 7 sheep in group A, 18 grafts in 9 sheep in group B) and artificially stenosed on the right side. The flow in the grafts in group A decreased from $297 \pm 118 \mathrm{ml} / \mathrm{min}$ to $158 \pm 159 \mathrm{ml} / \mathrm{min}$ $(p=0.041)$ after placement of the artificial stenosis in group $A$, and from $330 \pm 164 \mathrm{ml} / \mathrm{min}$ to $97 \pm 29 \mathrm{ml} / \mathrm{min} \quad(p=0.0052)$ in group $B(p=0.27$ between the groups). From the five surviving animals in group $A$, both grafts occluded in one animal 3 and 14 days after implantation. In group $B$, from the six surviving animals, only one graft on the left side remained patent $(p=0.0017)$. Histology showed degradation of the intimal layer in the center with endothelization from the periphery in group $A$ and formation of thick fibrous intimal layer in group B. We conclude that the ratio between collagen and lipid content in the novel three-layer graft plays a critical role in its patency and structural changes in vivo.
\end{abstract}

\begin{abstract}
Key words
Vascular graft • Collagen • Crosslinking • Extrusion • Composite tube $\bullet$ Patency • Sheep

Corresponding author

L. Lambert, Department of Radiology, First Faculty of Medicine, Charles University and General University Hospital in Prague, U Nemocnice 2, 12808 Prague 2, Czech Republic. Fax: +420 224963048. E-mail: lambert.lukas@gmail.com
\end{abstract}

\section{Introduction}

The long-term patency of prosthetic vascular grafts in the treatment of peripheral arterial disease depends on numerous factors including morphology of the anastomosis, graft diameter, and the outflow bed. In distal reconstructions and reconstructions with limited outflow, prosthetic grafts show worse patency rates than in proximal reconstructions (Chlupáč et al. 2009, Grus et al. 2017).

Our group has designed and manufactured a novel composite three-layer vascular graft. It is a composite tube on a biological basis with sandwich

PHYSIOLOGICAL RESEARCH • ISSN 0862-8408 (print) • ISSN 1802-9973 (online)

(c) 2019 Institute of Physiology of the Czech Academy of Sciences, Prague, Czech Republic

Fax +420 241062 164, e-mail: physres@fgu.cas.cz, www.biomed.cas.cz/physiolres 
construction of the wall where a polyester mesh is covered on both sides by collagen prepared from freshwater fish (Browning et al. 2012, McClure et al. 2012, Yamada et al. 2014). Previously, the immunological properties of carp collagen were tested and found comparable to or even better than the commonly used bovine collagen (Duan et al. 2009, Lambert et al. 2019, Yamamoto et al. 2014). We and other research groups tested different designs of vascular grafts with regard to similarity with a native vessel (Singh et al. 2015, Spacek et al. 2019, Veselý et al. 2015, Wise et al. 2011).

Preparation of collagen from a biological material follows numerous steps that include harvesting, cleaning, grinding, homogenization, crosslinking, and sterilization. Each of these steps influences properties of the final product. Specifically, crosslinking decreases compliance and thrombogenicity of the material (Terzi et al. 2018). The effect of the proportion of collagen and residual fat content which is influenced by its repeated dissolution and washing has not been explored yet.

In the present study, we manipulated the residual fat content in collagen used in this graft to influence its patency and biological properties that we further tested in an animal model.

\section{Materials and Methods}

This prospective study was approved by the institutional Animal Care and Use Committee and conducted in accordance with national Act No 246/1992 Coll. as amended on the protection of animals against cruelty, that is harmonized with the legislation of EU.
Two types of a composite three-layer vascular graft for low flow conditions with two carp collagen layers covering polyester mesh from both sides with an internal diameter of $5 \mathrm{~mm}$ were prepared (Grus et al. 2018, Spacek et al. 2019). The middle layer (Fig. 1) was knitted from a polyester monofilament (TDA Inc., Connenticut, USA) with a diameter of $34 \mu \mathrm{m}$ prepared by electrospinning on a flat double knitting machine (Faculty of Textile Engineering, Technical University in Liberec, Czech Republic) with 16 needles, 32 loops and then soaked in a solution with $4 \mathrm{~g} / 1 \mathrm{AEL}$ (nonionic tenside), $0.5 \mathrm{~g} / 1 \mathrm{Na}_{2} \mathrm{CO}_{3}$ at $80{ }^{\circ} \mathrm{C}$ for one hour, washed in chloroform for one hour, and finally thermally fixed at $160{ }^{\circ} \mathrm{C}$ for $10 \mathrm{~min}$ (Grus et al. 2018, Spacek et al. 2019). Mechanical and immunological properties of this graft have been tested previously (Lambert et al. 2019, Spacek et al. 2019).

Collagen was extracted from the skin of young $(\leq 2 \mathrm{~kg})$ scaleless carps. The skin was cleaned, frozen, and minced. This material was repeatedly dissolved in $0.1 \mathrm{M} \mathrm{NaOH}$ to remove excessive fat, washed, and again repeatedly dissolved in $10 \% \mathrm{n}$-butanol, filtered and washed. The number of dissolution cycles in $\mathrm{NaOH}$ was 5 in product $\mathrm{A}$ and 3 in product $\mathrm{B}$. Ultimately, collagen sheets were prepared by crosslinking in formaldehyde for 8 minutes (2.2\% Lyofix $\mathrm{CHN}$ ) and curing in $20 \%$ glycerine for $30 \mathrm{~min}$. In the final product, we estimated the content of dry matter, collagen, and fat, and measured the heat-shrink temperature. The middle layer was coated by collagen from both sides by extrusion creating a three-layer graft. The final product with an internal diameter of $5 \mathrm{~mm}$ was sterilized by gamma irradiation.
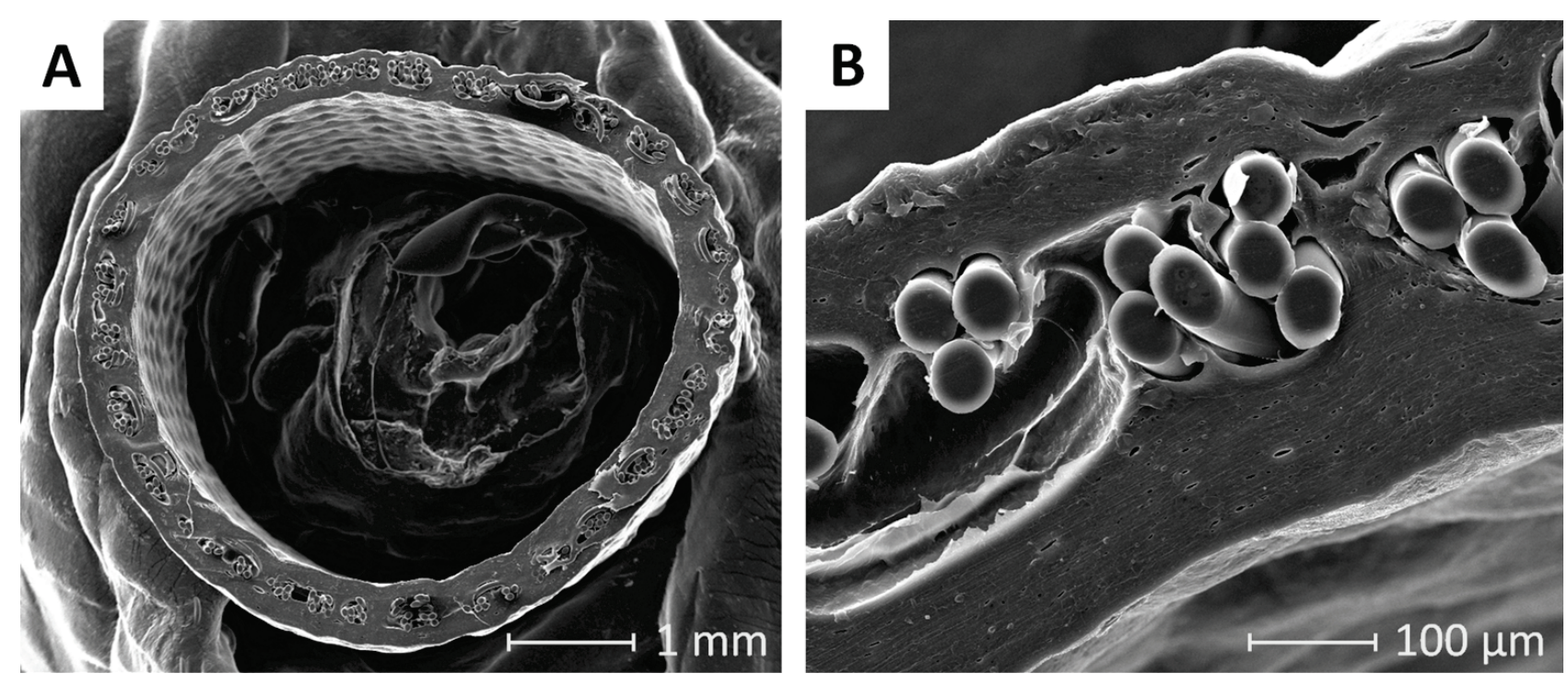

Fig. 1. MicroCT image of the novel three-layer graft. 

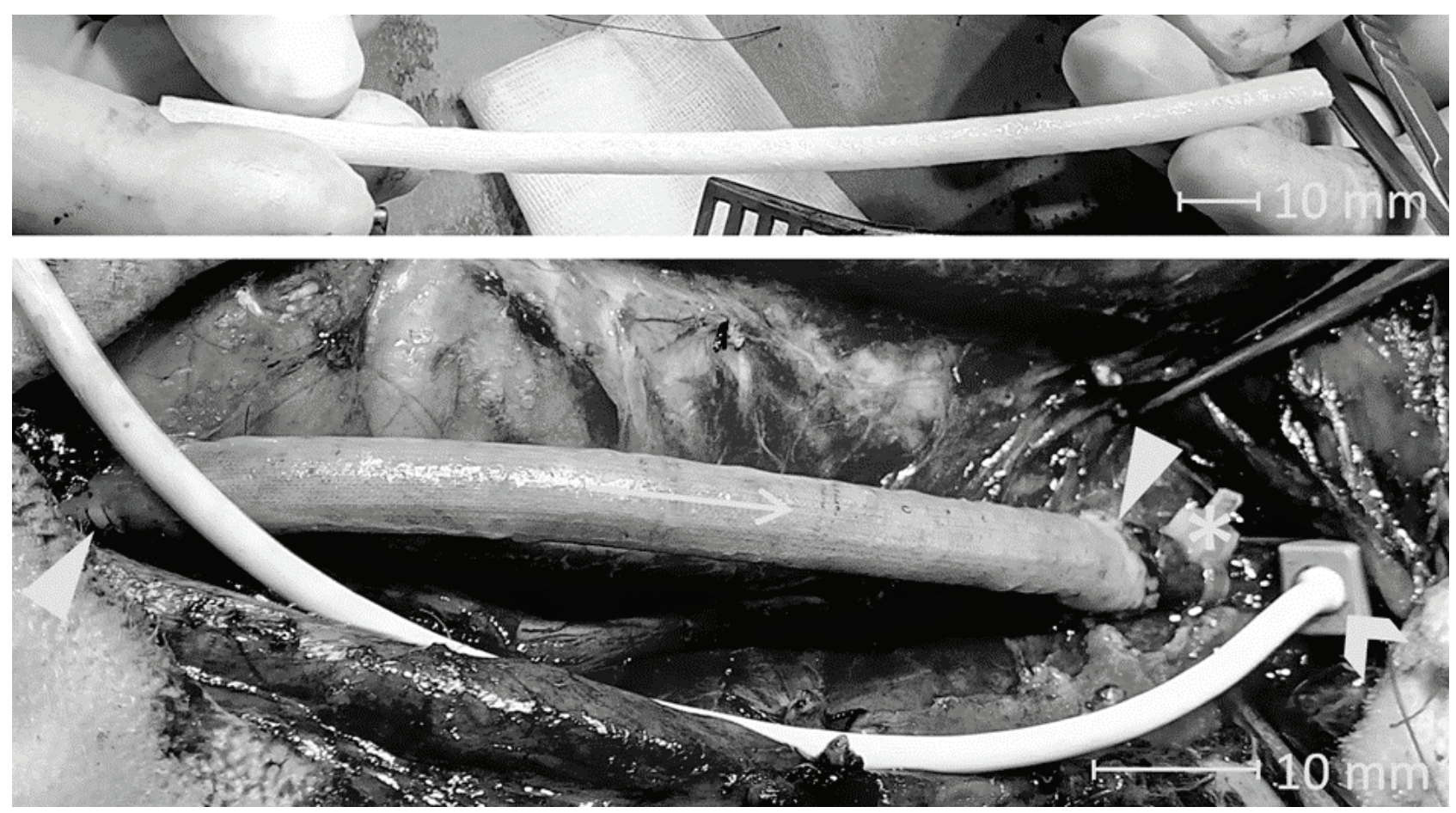

Fig. 2. Photograph of the graft ( $\varnothing=5 \mathrm{~mm}$ ) before (above) and after (below) implantation. Proximal and distal end of the anastomosis are marked with arrowheads. Arrow shows the direction of blood flow. Asterisk marks the plastic band used for artificial narrowing. The perivascular transient-time ultrasonic probe is marked by a chevron.

Table 1. Composition of collagen product $A$ and $B$ used in the inner and outer layer of the graft.

\begin{tabular}{lcc}
\hline & $\begin{array}{c}\text { Product A } \\
\text { (lower fat content) }\end{array}$ & $\begin{array}{c}\text { Product B } \\
\text { (higher fat content) }\end{array}$ \\
\hline Dry matter & $7 \%$ & $8 \%$ \\
Collagen in dry matter & $81 \%$ & $57 \%$ \\
Fat in dry matter & $6 \%$ & $34 \%$ \\
\hline
\end{tabular}

The grafts were trimmed to a length of approx. $15 \mathrm{~cm}$ and implanted end-to-side in both carotid arteries in a sheep by two experienced vascular surgeons during general inhalation anesthesia (Fig. 2). There were 14 grafts coated with product A implanted in 7 sheep (group A) and 18 grafts coated with product B implanted in 9 sheep (group B). The sheep were $6.3 \pm 1.0$ years old, weighted $53 \pm 14 \mathrm{~kg}$, and $12(75 \%)$ were ewes. Flow in the carotid artery and graft were measured using a perivascular transient-time ultrasonic probe (Transonic Inc., Ithaca, NY) before and after implantation. In all animals, the outflow artery was artificially narrowed by placing a plastic band on one side (Fig. 2) to limit the flow to $100-150 \mathrm{ml} / \mathrm{min}$, and the flow was re-measured. Postoperatively, all animals were receiving acetylsalicylic acid (Anopyrin 100 mg, Zentiva, Czech Republic). The patency of the grafts was assessed by ultrasound (Acuson
$\mathrm{X} 150^{\mathrm{TM}}$, Siemens Healthcare, Munich, Germany) and the general status of the animals was checked on a regular basis. The animals were terminated when 1) they were not thriving or could not recover from anesthesia, 2 ) the graft occluded, or 3 ) after a period of 26 weeks. The grafts were explanted for histological analysis. The specimens were processed with the paraffin technique and stained with hematoxylin and eosin (H\&E) with Weigert's resorcin-fuchsin (elastin).

\section{Results}

Product A had higher content of collagen and lower content of fat compared to product B (Table 1). The heat-shrink temperature in product $\mathrm{A}$ and $\mathrm{B}$ was comparable with $43.1^{\circ} \mathrm{C}$ and $43.7^{\circ} \mathrm{C}$, respectively. When handling, product $\mathrm{B}$ with higher fat content was more 
compliant with better cohesion of the layers while product A was tougher, more brittle, with suboptimal cohesion of the layers.

In each group, two animals did not fully recover from the anesthesia. One animal in group A and one animal in group $\mathrm{B}$ were terminated at 51 and 5 days for failure to thrive. In group A, two grafts in one animal occluded in the first two weeks, but in group B, early closure was observed in five animals (Fig. 3). The flow through the graft was comparable between the study groups and the left and right side (Table 2). After artificial narrowing, the flow in the graft diminished by $47 \%$ in group $\mathrm{A}$ and by $71 \%$ in group B, but the difference between the groups was not significant $(p=0.28)$. Histological analysis showed that grafts that were in situ for at least three weeks induced cellular reaction in the outer layer. Grafts from group A showed areas of exposed polyester mesh in the central portion with signs of patchy to sub-confluent endothelization towards the periphery (Fig. 4). Graft from group B developed a thick fibrous intimal layer (Fig. 5).

\section{Discussion}

This study showed that the use of carp collagen with lower fat content (product A) in a novel composite three-layer graft with sandwich construction of the wall results in better patency rates. Both collagens showed tendency to incorporate in the surrounding tissue. Grafts coated with higher carp collagen content (product A) show degradation of the intimal layer and reendothelization from the periphery while grafts with higher lipid content (product B) tend to develop a thick fibrous intimal layer.

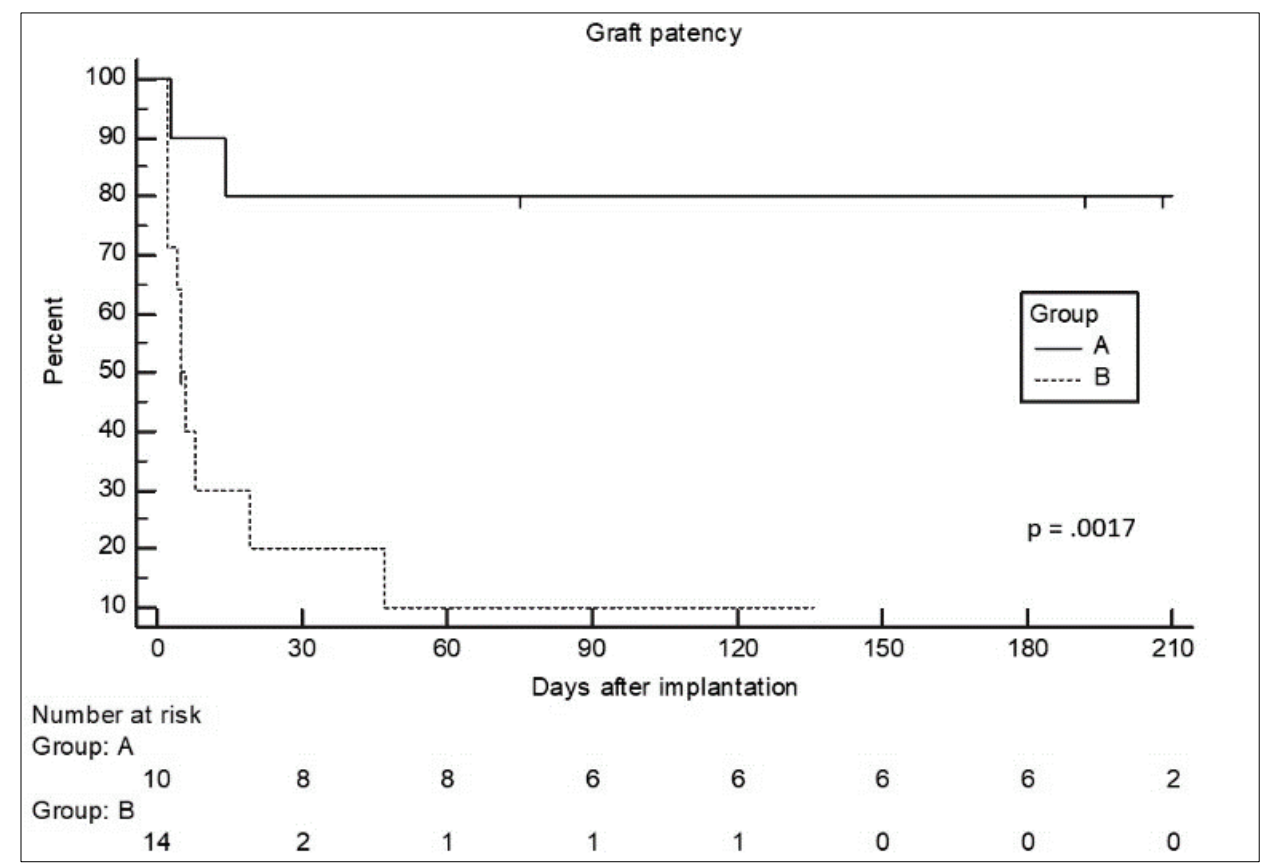

Fig. 3. Kaplan-Meier plot of graft patency rates shows clear difference between group A (lower fat content collagen) and group B (higher fat content collagen) with $p=0.0031$ according to the log-rank test.

Table 2. Flow rates before and after implantation of the graft, after artificial narrowing of the right side to limit flow through the graft, and at the end of the experiment in animals with patent grafts. The graft implanted in group A was coated with collagen with lower fat content (product A) compared to the graft used in group B (see Table 1).

\begin{tabular}{lllcccccc}
\hline Group & Side & $\begin{array}{c}\text { Flow Initial } \\
{[\mathbf{m l} / \mathbf{m i n}]}\end{array}$ & $\begin{array}{c}\text { Flow after graft } \\
\text { placement } \\
{[\mathbf{m l} / \mathbf{m i n}]}\end{array}$ & $\mathbf{p}^{\mathbf{1}}$ & $\begin{array}{c}\text { Flow after } \\
\text { narrowing } \\
{[\mathbf{m l} / \mathbf{m i n}]}\end{array}$ & $\mathbf{p}^{\mathbf{1}}$ & $\begin{array}{c}\text { Flow at } \\
\text { the end } \\
{[\mathbf{m l} / \mathbf{m i n}]}\end{array}$ & $\mathbf{p}^{\mathbf{1}}$ \\
\hline$A$ & Left & $350 \pm 120$ & $287 \pm 113$ & 0.1434 & & & $355 \pm 102$ & 0.42 \\
$A$ & Right & $309 \pm 134$ & $297 \pm 118$ & 0.7645 & $158 \pm 159$ & 0.0411 & $147 \pm 10$ & 0.64 \\
$B$ & Left & $330 \pm 170$ & $311 \pm 123$ & 0.5674 & & & 175 & $\mathrm{x}$ \\
$B$ & Right & $318 \pm 137$ & $330 \pm 164$ & 0.7719 & $97 \pm 29$ & 0.0052 & 110 & $\mathrm{x}$ \\
\hline
\end{tabular}

${ }^{1}$ paired t-test 

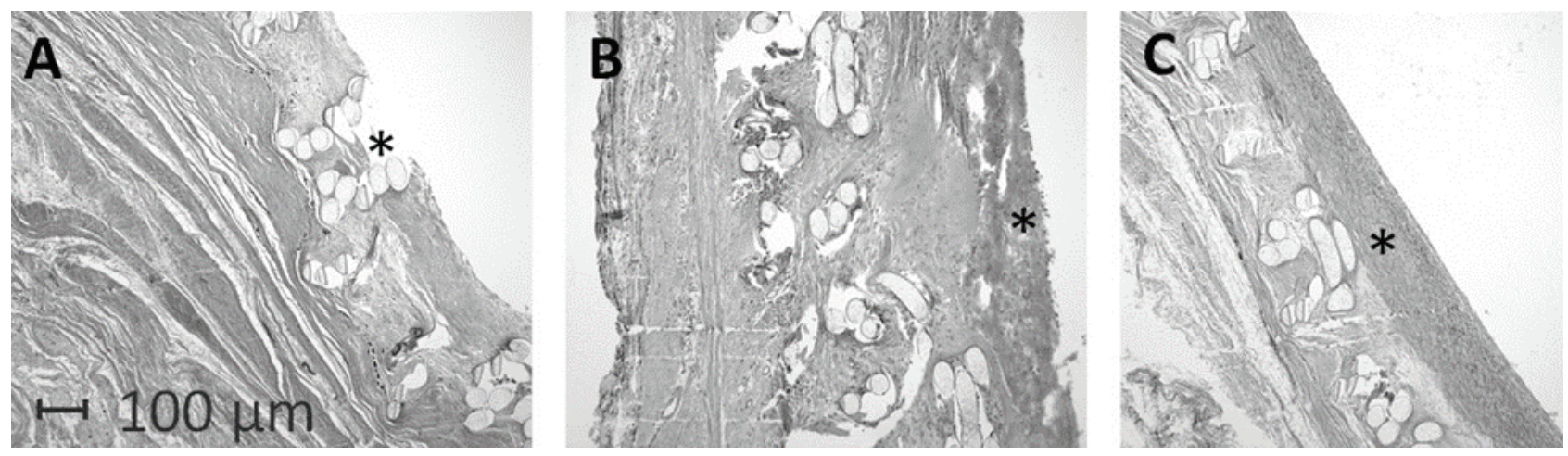

Fig. 4: Microscopic image (H\&E) of an explanted graft shows: a) areas of exposed polyester mesh in the center, b) intimal hyperplasia, and c) mild fibrous thickening of the intimal layer towards the periphery of the graft indicating neoendothelisation in an animal from group A (lower fat content collagen), all marked by an asterisk.
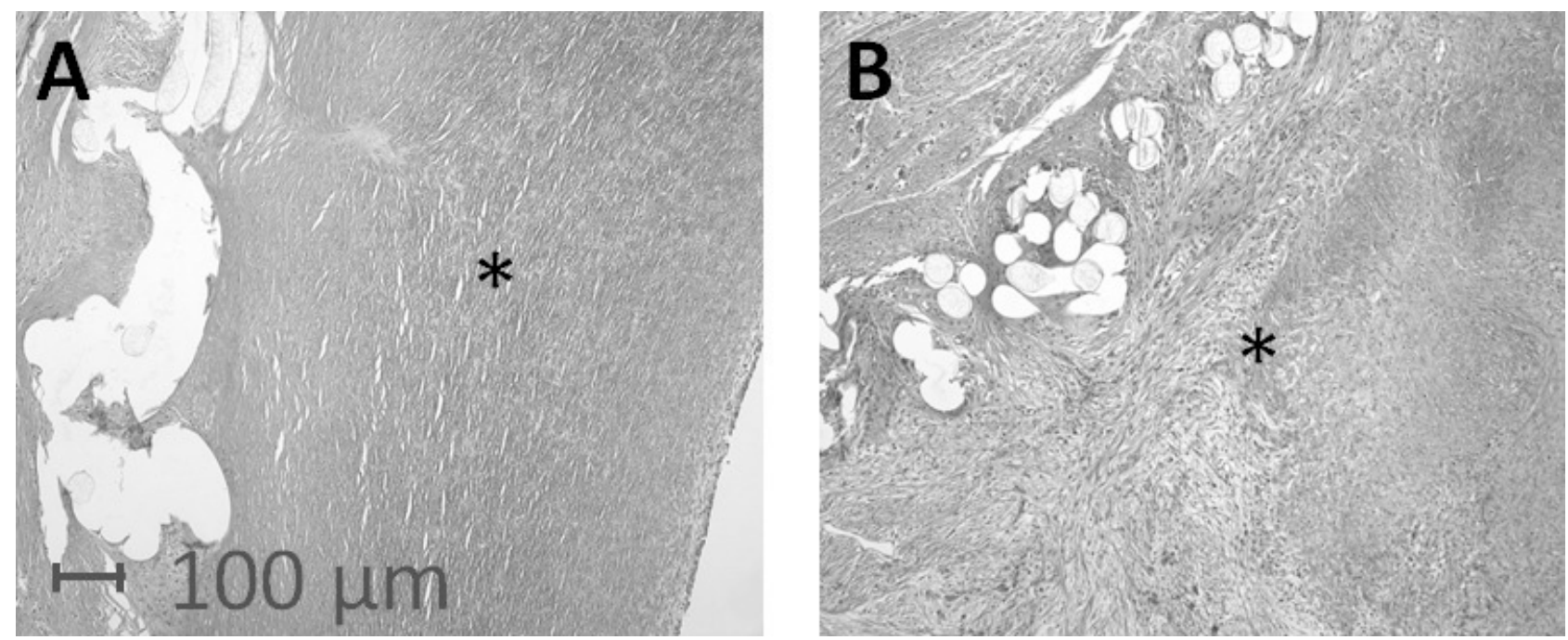

Fig. 5. Microscopic image (H\&E) of an explanted graft shows marked fibrous thickening of the intimal layer in two animals from group $\mathrm{B}$ (higher fat content collagen), marked by an asterisk.

Prosthetic vascular grafts are an alternative to autologous grafts if they are not available in sufficient length or quality. Generally, their long-term performance is inferior to autologous grafts, but some studies have shown, that it may be even comparable in proximal reconstructions (Rychlik et al. 2014). In our design of a three-layer vascular graft, we aimed to mimic the structure of an autologous vessel and approximate its mechanical and physical properties as much as possible (Spacek et al. 2019, Veselý et al. 2015). For this, we tested various constructions of the vessel wall and structures of the scaffold in previous studies (Grus et al. 2018, Spacek et al. 2019).

The fabric and construction of a prosthetic vascular graft has an effect on its long-term patency as well (Sarkar et al. 2007). Currently, two types of grafts are in clinical use: the expanded polytetrafluorethylene (ePTFE) graft, and knitted grafts made from polyester with several modifications of the graft structure and inner wall coating. Several graft construction types including bi- or multi-layered design have been proposed and investigated even by our research group (Chlupáč et al. 2009, Spacek et al. 2019). Coating of the inner layer by a modified mesh to improve wettability and neoendothelization of the graft have been proposed and tested in animal models but were not used in patients (Grus et al. 2018). In this study, we showed, that modification of a single step in purification of the collagen impacts the balance between degradation of the artificial intima, neoendothelization, and proliferation and hypertrophy of this layer. The primary idea of modifying the ratio between the collagen content and residual fat was to decrease wettability of the inner layer because pure collagen is a hemostatic agent.

As Zilla et al. (Zilla et al. 2007) indicated, the ingrowth of the intima from the native vessel to the 
periphery of the graft is not as desirable as transmural reendothelization along the whole length of the graft. In group A (lower fat content in collagen), we observed the first pattern. In group $B$, we believe that the latter phenomenon prevailed, but it was too intense that it resulted in stenosis and ultimately occlusion of the vessel. The residual fat content in the collagen layer, which was higher in group B, may dissolve from the mesh, which results in rarefaction of the inner layer, increased porosity, and throughput. We assume that accelerated release of the fat from the inner layer in group B resulted in increased porosity and exposure of collagen fibers and thus increased adhesion of fibrin and platelets forming a thick neointimal fibrinous layer.

Mechanical properties of a vascular graft in terms of handling and constructing an anastomosis are important. We noted that product $\mathrm{B}$ with higher fat content was easier to handle due to its better compliance and cohesion of the layers, but this also resulted in greater tortuosity and propensity to kinking. Product A with lower fat content was more difficult to suture, and attention had to be paid not to dissociate its layers, but its shape was more stable.

Extracted carp collagen has a heat-shrink temperature about $20{ }^{\circ} \mathrm{C}$ which increases with crosslinking, in our study to $43{ }^{\circ} \mathrm{C}$. Normal body temperature of a sheep is $39^{\circ} \mathrm{C}$ which is close to this temperature and this also may have had impact on the stability of the collagen layer, its wettability, thrombogenicity, porosity, and throughput, which should not exceed 3.000 $\mathrm{ml} / \mathrm{min} / \mathrm{cm}^{2} / 120 \mathrm{mmHg}$. Further design of the graft therefore would need to address this issue by longer time for cross-linking (Vesely et al. 2015). It should be noted that sterilization by gamma rays increases the crosslinking rate (Matuska and McFetridge 2015). Crosslinking increases stiffness of the material and has another side effect of changing the epitopes of the collagen macromolecule that are responsible for its hemostatic properties and therefore may contribute to decreased thrombogenicity (Chan and Leong 2008, Terzi et al. 2018, Wise et al. 2011). Also, formaldehyde should be replaced by a different non-carcinogenic crosslinking agent, when used in humans.

The outer layer plays a role in incorporation of the graft into the surrounding structures. In our study, the manipulated properties of the collagen showed little influence on cellular migration into the outer artificial collagen layer.

Apart from graft type, there are several factors known to influence long term patency of the reconstruction. Previously, our group and others have demonstrated the favorable effect of constructing an anastomosis with an acute angle, or the choice of the graft diameter similar or slightly greater than the target artery (Grus et al. 2009, Grus et al. 2016a, Grus et al. 2016b). In our experiment, we constructed a graft with a diameter of $5 \mathrm{~mm}$, which is similar to that of the carotid artery in a sheep. However, experimental manipulation of the flow could have tipped the balance towards lower wall shear stress and increased thrombogenicity (Zhou et al. 2014). On the other hand, increased wall shear stress may accelerate degradation of the inner layer and impede formation of the neointima. The anastomosis undergoes remodeling that promotes laminar flow in the first postoperative months as well (Grusova et al. 2018).

This study has several limitations. Firstly, the number of surviving animals especially in group B (higher fat content) was small. Secondly, the flow on the artificially stenosed side in group B was slightly, albeit not significantly, smaller. Thirdly, the experiment was carried out on an animal model and its results cannot be fully translated to human patients. Further study with longer follow-up is warranted to assess graft patency in long-term.

\section{Conclusions}

This study showed that modification of the fat content of collagen used in the outer and inner layer of a novel composite three-layer vascular graft plays a critical role in its patency and structural changes in the intimal layer.

\section{Conflict of Interest}

There is no conflict of interest.

\section{Acknowledgements}

This work was supported by Ministry of Health of the Czech Republic (grant 15-27941A) and by the grant SVV-2019 - 260372. 


\section{References}

BROWNING MB, DEMPSEY D, GUIZA V, BECERRA S, RIVERA J, RUSSELL B, HÖÖK M, CLUBB F, MILLER M, FOSSUM T, DONG JF, BERGERON AL, HAHN M, COSGRIFF-HERNANDEZ E: Multilayer vascular grafts based on collagen-mimetic proteins. Acta Biomater 8: 1010-1021, 2012.

CHAN BP, LEONG KW: Scaffolding in tissue engineering: general approaches and tissue-specific considerations. Eur Spine J 17: 467-479, 2008.

CHLUPÁČ J, FILOVÁ E, BACÁKOVÁ L: Blood vessel replacement: 50 years of development and tissue engineering paradigms in vascular surgery. Physiol Res 58 Suppl 2: S119-139, 2009.

DUAN R, ZHANG J, DU X, YAO X, KONNO K: Properties of collagen from skin, scale and bone of carp (Cyprinus carpio). Food Chem 112: 702-706, 2009.

GRUS T, GRUSOVA G, LAMBERT L, BANERJEE R, MATECHA J, MLCEK M: The influence of the anastomosis angle on the hemodynamics in the distal anastomosis in the infrainguinal bypass: an in vitro study. Physiol Res 65: 591-595, 2016a.

GRUS T, LAMBERT L, GRUSOVA G, LUKAC P, HRUBY J, LINDNER J: Branched crural bypass has no advantage over simple crural bypass in the treatment of peripheral arterial disease. Int J Clin Exp Med 10: 7859-7866, 2017.

GRUS T, LAMBERT L, MATĚCHA J, GRUSOVÁ G, ŠPAČEK M, MLČEK M: The ratio of diameters between the target artery and the bypass modifies hemodynamic parameters related to intimal hyperplasia in the distal endto-side anastomosis. Physiol Res 65: 901-908, 2016b.

GRUS T, LAMBERT L, MLCEK M, CHLUP H, HONSOVA E, SPACEK M, BURGETOVA A, LINDNER J: In vivo evaluation of short-term performance of new three-layer collagen-based vascular graft designed for low-flow peripheral vascular reconstructions. Biomed Res Int 2018: 3519596, 2018.

GRUS T, LINDNER J, VIDIM T, TOSOVSKY J, MATECHA J, ROHN V, LAMBERT L, GRUSOVA G: The anastomosis angle is a key to improved long-term patency of proximal femoropopliteal bypass. Ann Vasc Surg 23: 598-605, 2009.

GRUSOVA G, LAMBERT L, KAVAN J, LAMBERTOVA A, BURGETOVA A, MLCEK M, GRUS T: Natural remodeling of the distal anastomosis of an above-knee femoropopliteal bypass depicted by CT angiography of lower limbs improves geometry of the reconstruction. Physiol Res 67: 857-862, 2018.

LAMBERT L, NOVAKOVA M, LUKAC P, CECHOVA D, SUKENIKOVA L, HRDY J, MLCEK M, CHLUP H, SUCHY T, GRUS T: Evaluation of the immunogenicity of a vascular graft covered with collagen derived from the european carp (cyprinus carpio) and bovine collagen. Biomed Res Int 2019: 5301405, 2019.

MATUSKA AM, MCFETRIDGE PS: The effect of terminal sterilization on structural and biophysical properties of a decellularized collagen-based scaffold; implications for stem cell adhesion. J Biomed Mater Res B Appl Biomater 103: 397-406, 2015.

MCCLURE MJ, SIMPSON DG, BOWLIN GL: Tri-layered vascular grafts composed of polycaprolactone, elastin, collagen, and silk: Optimization of graft properties. J Mech Behav Biomed Mater 10: 48-61, 2012.

RYCHLIK IJ, DAVEY P, MURPHY J, O'DONNELL ME: A meta-analysis to compare Dacron versus polytetrafluroethylene grafts for above-knee femoropopliteal artery bypass. J Vasc Surg 60: 506-515, 2014.

SARKAR S, SCHMITZ-RIXEN T, HAMILTON G, SEIFALIAN AM: Achieving the ideal properties for vascular bypass grafts using a tissue engineered approach: a review. Med Biol Eng Comput 45: 327-336, 2007.

SINGH C, WONG CS, WANG X: Medical textiles as vascular implants and their success to mimic natural arteries. J Funct Biomater 6: 500-525, 2015.

SPACEK M, CHLUP H, MITAS P, VESELY J, LAMBERT L, MLCEK M, KRAJICEK M, LINDNER J, GRUS T: Three-layer collagen-based vascular graft designed for low-flow peripheral vascular reconstructions. $J$ Appl Biomed 17: 47-52, 2019.

TERZI A, STORELLI E, BETTINI S, SIBILLANO T, ALTAMURA D, SALVATORE L, MADAGHIELE M, ROMANO A, SILIQI D, LADISA M, DE CARO L, QUATTRINI A, VALLI L, SANNINO A, GIANNINI C: Effects of processing on structural, mechanical and biological properties of collagen-based substrates for regenerative medicine. Sci Rep 8: 1429, 2018. 
VESELÝ J, HORNÝ L, CHLUP H, ADAMEK T, KRAJIČCK M, ŽITNÝ R: Constitutive modeling of human saphenous veins at overloading pressures. J Mech Behav Biomed Mater 45: 101-108, 2015.

VESELY J, HORNÝ L, CHLUP H, BERAN M, KRAJICEK M, ŽITNÝ R: Effect of polyvinyl alcohol concentration on the mechanical properties of collagen/polyvinyl alcohol blends. Appl Mech Mater 732: 161-164, 2015.

WISE SG, BYROM MJ, WATERHOUSE A, BANNON PG, NG MKC, WEISS AS: A multilayered synthetic human elastin/polycaprolactone hybrid vascular graft with tailored mechanical properties. Acta Biomater 7: 295-303, 2011.

YAMADA S, YAMAMOTO K, IKEDA T, YANAGIGUCHI K, HAYASHI Y: Potency of fish collagen as a scaffold for regenerative medicine. Biomed Res Int 2014: 302932, 2014, doi: 10.1155/2014/302932

YAMAMOTO K, IGAWA K, SUGIMOTO K, YOSHIZAWA Y, YANAGIGUCHI K, IKEDA T, YAMADA S, HAYASHI Y: Biological safety of fish (tilapia) collagen. Biomed Res Int 2014: 630757, 2014. doi: $10.1155 / 2014 / 630757$

ZHOU J, LI Y-S, CHIEN S: Shear stress-initiated signaling and its regulation of endothelial function. Arterioscler Thromb Vasc Biol 34: 2191-2198, 2014.

ZILLA P, BEZUIDENHOUT D, HUMAN P: Prosthetic vascular grafts: Wrong models, wrong questions and no healing. Biomaterials 28: 5009-5027, 2007. 